\title{
0 critério espacial do IPVA e a guerra fiscal entre os Estados ${ }^{1}$
}

The criterion space of the automobile taxes and tax war between the M ember

Tiago Landi Simões ${ }^{2}$

\section{Resumo}

O IPVA é um imposto relativamente recente no cenário jurídico nacional, tendo sido instituído somente em 1985, sendo, portanto, carecedor de maiores lucubrações pela doutrina. Embora pareça, à primeira vista, um imposto de critérios ou parâmetros simples, cuja aplicação decorra da literalidade da lei, na realidade o IPVA é cercado de controvérsias, dentre elas a polêmica concernente ao critério espacial da hipótese de incidência que, conjugado às diferentes alíquotas estipuladas por cada Estado-membro, propicia o surgimento da propalada guerra fiscal.

Palavras Chave: IPVA; Regra-Matriz de Incidência Tributária; Critério Espacial; Guerra Fiscal; Alíquota.

\section{Abstract}

IPVA The tax is a relative newcomer to the national legal scene, having been established only in 1985, and is therefore more carecedor vagaries of the doctrine. Although it seems at first glance, a tax criteria or simple parameters, which result from the literal application of the law, in reality the IPVA is surrounded by controversy, among them the controversy concerning the spatial criterion of the hypothesis that incidence, combined with different rates set by each member State, gives the appearance of the vaunted war tax.

Keywords: IPVA; Rule Tax Incidence-M atrix; Criterion Space, War Tax, Rate.

\section{Introdução}

A República Federativa do Brasil, dotada do poder tributário ideal, reparte-o entre os entes que compõem a Federação: a União, os Estados, o Distrito Federal e os M unicípios. De fato, inexiste hierarquia jurídica entre os entes da federação, pois são todos pessoas jurídicas dotadas de plena capacidade política, atuantes dentro de suas esferas de

\footnotetext{
${ }^{1}$ Trabalho apresentado como parte integrante da avaliação do 40 bimestre para a Disciplina de Direito Tributário da Universidade Estadual de Londrina.

${ }^{2}$ Acadêmico do 50 ano do Curso de Direito da Universidade Estadual de Londrina.
} 
competência, traçadas pela Constituição da República.

As competências tributárias, portanto, foram distribuídas pela Carta M agna entre os entes políticos que constituem a Federação, e tais competências consistem na aptidão de que são dotados estes entes para expedir regras jurídicas tributárias, inovando o ordenamento positivo.

No campo da competência tributária destacam-se as normas instituídas pelas pessoas políticas que tratam da incidência fiscal, pois visam tais normas jurídicas regular a principal figura do Direito Tributário, de enorme relevância para o Poder Público: os impostos.

O presente trabalho pretende analisar a norma de incidência tributária aplicada ao IPVA segundo a teoria proposta pelo professor Paulo de Barros Carvalho, focalizando em especial o critério espacial da norma, ou seja, buscando determinar o campo territorial de incidência da norma, requisito para que faça surgir seus efeitos.

A correta definição do critério espacial é fundamental para conhecer o tributo em sua essência, mormente no caso do IPVA, cuja competência tributária é concorrente, atribuída a diversos entes de que possuem territórios únicos e distintos.

\section{A regra-matriz de incidência tributária}

Toda ciência se baseia em um modelo de rigor, no qual as palavras detêm uma significação única, capaz de proporcionar ao cientista a máxima precisão e objetividade em suas conclusões. Desta qualidade intrínseca ao método científico não escapa a Ciência do Direito Tributário, que como qualquer outro ramo didaticamente autônomo do Direito necessita estabelecer premissas lógicas e não contraditórias para o equilíbrio de seu sistema.

Diante da ambigüidade existente no direito positivo pátrio quanto ao significado da expressão fato gerador, ora se referindo à previsão abstrata do fato e ora se referindo ao fato concreto que faz surgir a obrigação tributária, o professor Paulo de Barros Carvalho construiu a teoria da regra-matriz de incidência tributária, dotada de termos distintos daqueles utilizados no Código Tributário Nacional, objetivando uma maior clareza no estudo dos fenômenos tributários.

Segundo a teoria de Carvalho (2004, p. 245), dá-se o nome de hipótese tributária à construção de linguagem prescritiva geral e abstrata do fato, enquanto se denomina fato 
jurídico tributário a sua projeção factual. Quando o fato jurídico tributário se subsume à hipótese tributária (antecedente da regra-matriz), surgem os efeitos jurídicos prescritos no conseqüente da regra-matriz, unindo sujeito ativo e passivo numa relação jurídica que tem como objeto o tributo em espécie.

No escólio de Carvalho (2004, p. 251-264), no antecedente da regra-matriz sobrelevam-se três critérios fundamentais para a identificação do tributo: 0 critério material, (indica o comportamento de alguma pessoa), o critério espacial (define o território em que o comportamento terá relevância) e o critério temporal (estabelece quando o comportamento será relevante). 0 conseqüente da regra-matriz tem um conteúdo prescritor, composto de dois critérios: 0 critério pessoal (indica quais os sujeitos da relação jurídica tributária) e 0 critério quantitativo (diz respeito ao objeto da prestação que, no caso da regra-matriz de incidência tributária, se consubstancia na base de cálculo e na alíquota).

A união de todos os critérios fornece ao intérprete da norma jurídica tributária a possibilidade de abstrair o núcleo lógico-estrutural da norma-padrão, preenchido com os requisitos significativos necessários e suficientes para a imposição da exação.

\section{0 imposto sobre a propriedade de veículos automotores (IPVA)}

O IPVA é um imposto relativamente recente no cenário jurídico nacional, tendo em conta que não encontra previsão no Código Tributário Nacional, publicado em 25 de outubro de 1966.

Suas origens remontam à taxa remuneratória de serviço instituída pela Constituição da República de 1967, cujo regime autorizava a União, os Estados, o Distrito Federal e os Municípios cobrarem taxas pelo uso de determinados serviços, dentre eles o uso de suas rodovias. Em 1968 sobreveio a taxa rodoviária federal, precursora do atual imposto sobre veículos automotores, cuja receita era aplicada integralmente no custeio de projetos e obras de conservação e restauração de estradas de rodagem federais (M AM EDE, 2002, p. 30).

Em 1969 o Governo Federal aboliu a possibilidade de concomitância de taxas e criou a taxa rodoviária única (TRU), devida pelos proprietários de veículos automotores registrados e licenciados no território nacional. Posteriormente, no ano de 1985, ainda sob a égide da Constituição de 1967 (com as alterações introduzidas pela Emenda 1/1969), foi extinta a TRU e criado o IPVA, que foi mantido na esfera de competência dos Estados e do 
Distrito Federal pelo artigo 155, III, da Constituição da República de 1988 (MAM EDE, 2002, p. $31)$.

Em face da inexistência de Lei Complementar que regule nacionalmente o IPVA, seus limites foram estabelecidos por cada ente tributário competente através de leis estaduais ou distritais, respeitados os princípios maiores do Código Tributário Nacional (SEGUNDO, 2007, p. 177). Cada ente, portanto, é legitimado para estabelecer como será instituído, cobrado e fiscalizado o imposto, dispondo acerca do seu pagamento, da base de cálculo, das alíquotas, das isenções, das anistias, dos sujeitos da obrigação, das obrigações acessórias, das penalidades etc.

Muitos são os pontos de conflito entre as diversas legislações do país que disciplinam o IPVA, principalmente em função da ausência de uma Lei Complementar que estabeleça parâmetros objetivos de observância obrigatória para os Estados e para o Distrito Federal.

Além desta ausência de norma nacional regulamentadora, a doutrina é econômica no que tange à análise do IPVA, com escassas publicações acerca do tema, gerando a falsa impressão de que são poucas as controvérsias que circundam este imposto. 0 que se percebe, na realidade, é que em todos os critérios da regra-matriz há controvérsias ou questões ainda não definidas por completo. Por exemplo, são temas que ainda hoje geram acerbada polêmica: a extensão da expressão veículo automotor para efeito de incidência do IPVA, sucessão de contribuintes, seletividade das alíquotas, dentre outros.

Entretanto, a par as inúmeras controvérsias acerca do tema, o presente trabalho terá seu enfoque no critério espacial do IPVA, ou seja, o plano territorial de aplicação da lei tributária.

\section{Critério espacial do IPVA}

Numa primeira análise superficial, considerando unicamente 0 artigo 155, III, da Constituição da República, que determina competir aos Estados e ao Distrito Federal instituírem imposto sobre a propriedade de veículos automotores, a conclusão lógica a que se chega é de que o IPVA será devido sobre os veículos automotores localizados neste ou naquele Estado ou Distrito Federal.

Todavia, o fato do IPVA tributar a propriedade de um bem móvel por natureza, 
próprio para o transporte, seja dentro do Estado ou além de seus limites, traz dificuldades práticas para a definição de seu critério espacial. Afinal, a Constituição se restringe a apontar o ente competente para a instituição do imposto, não dizendo coisa alguma a respeito de onde será ele devido.

Assim sendo, considerando tão-somente o mandamento constitucional ventilado, estariam os Estados ou o Distrito Federal livres para cobrar o imposto sobre a propriedade do veículo automotor considerando o domicílio do proprietário, o local da compra do veículo, o local do registro e licenciamento, o local do uso habitual do veículo etc. Cada ente tributário estabeleceria o critério espacial do imposto conforme melhor the aprouvesse, trazendo maior arrecadação para os cofres públicos.

Contudo, desnecessárias maiores elucubrações para se concluir que tal multiplicidade de critérios levaria a uma desordem generalizada, lesiva ao contribuinte que seria tributado por diversos entes distintos pelo mesmo fato.

De fato, inexiste na Constituição da República ou em lei federal regra explícita a respeito do critério espacial a ser utilizado pelos Estados e pelo Distrito Federal no IPVA, mas esta regra pode ser inferida através de uma interpretação sistemática do ordenamento jurídico:

Há regras jurídicas que trazem expressos os locais em que o fato deve ocorrer, a fim de que irradie os efeitos que lhe são característicos. Outras, porém, nada mencionam, carregando implícitos os indícios que nos permitem saber onde nasceu o laço obrigacional. É uma opção do legislador. Aquilo que de real encontramos, no plano do direito positivo brasileiro, é uma dose maior ou menor de esmero na composição dos critérios espaciais, de tal modo que alguns são elaborados com mais cuidado que outros. Todavia, ainda que aparentemente pensemos ter o político se esquecido de mencioná-lo, haverá sempre um plexo de indicações, mesmo tácitas e latentes, para assinalar o lugar preciso em que aconteceu aquela ação, tomada como núcleo do suposto normativo (CARVALHO, 2004, p. 256).

Se pudesse o legislador extrair a mais justa das regras para definir o critério espacial, este seria o do local de uso habitual do veículo automotor, afinal, é o Estado em que mais circula determinado veículo que terá de arcar com os custos proporcionados pelo tráfego constante deste veículo, o que gerará, decerto, gastos com pavimentação, sinalização, remuneração dos oficiais de trânsito etc. Embora seja vedada a vinculação de receita dos impostos a órgão, fundo ou despesa, nos termos do artigo 167, IV, da 
Constituição da República, é óbvio que grande parte da receita obtida com o IPVA é utilizada pelos Estados e pelo Distrito Federal naquelas atividades.

É claro que esta é uma situação ideal e impossível de ser implementada na prática, pelo menos no atual panorama da ordem jurídica nacional. Esta hipótese exigiria a instalação obrigatória de um dispositivo rastreador em cada veículo industrializado, esbarrando também noutro óbice de natureza constitucional: a inviolabilidade da intimidade e da vida privada dos cidadãos, garantia fundamental inscrita no artigo $50, X$, da Constituição.

Apesar de não haver previsão expressa do critério espacial do IPVA na Constituição ou em norma nacional, como já destacado, seus moldes podem ser deduzidos por uma interpretação histórico-sistemática do ordenamento jurídico brasileiro.

Partindo-se da interpretação histórica, sabe-se que a já extinta Taxa Rodoviária Unificada (TRU), precursora do atual IPVA, era cobrada previamente ao registro de veículo ou à renovação anual da licença para circular. 0 critério espacial escolhido pelo legislador de outrora, destarte, era o local do registro ou da renovação da licença para circular.

Com a promulgação da Constituição Federal de 1988, que manteve a competência dos Estados e do Distrito Federal para instituir e cobrar o IPVA, que havia sido criado em 1985, a aferição do critério espacial do IPVA carece de um exame sistêmico, no qual se integram, além da própria Constituição, o Código Tributário Nacional, o Código de Trânsito Brasileiro e o Código Civil.

Além da disposição genérica traçada no artigo 155, III, a Constituição da República fixa também como regra, no artigo 158, III, pertencer aos M unicípios cinqüenta por cento do produto da arrecadação do imposto do Estado sobre a propriedade de veículos automotores licenciados em seus territórios. Vê-se aí, portanto, menção direta ao licenciamento do veículo, indicação a ser seguida pelos legisladores estaduais e distrital no desenho do critério espacial do IPVA.

A Lei no 9.503/1997, que instituiu o Código de Trânsito Brasileiro, dispõe acerca do registro e do licenciamento dos veículos automotores nos artigos 120 e 130, respectivamente: 
Federal, no M unicípio de domicílio ou residência de seu proprietário, na forma da lei.

$(\ldots)$

Art. 130. Todo veículo automotor, elétrico, articulado, reboque ou semi-reboque, para transitar na via, deverá ser licenciado anualmente pelo órgão executivo de trânsito do Estado, ou do Distrito Federal, onde estiver registrado o veículo.

0 registro e licenciamento são, por conseguinte, obrigatórios, devendo ser efetuados perante o órgão executivo de trânsito do Estado ou do Distrito Federal (DETRAN), no Município de domicílio ou residência de seu proprietário. Fica então impossibilitado o contribuinte de registrar seu veículo no DETRAN de Estado no qual não possua domićlio ou residência, por expressa imposição legal. Aquele que declara falso domicílio para registrar ou licenciar seu veículo incorre ainda em sanção administrativa, esboçada no artigo 242 do Código de Trânsito:

Art. 242. Fazer falsa declaração de domicílio para fins de registro, licenciamento ou habilitação:

Infração - gravíssima; Penalidade - multa.

o Código Tributário Nacional trata do domicílio para efeitos tributários em seu artigo 127, utilizando-se das mesmas linhas que delimitam o conceito de domićlio no Código Civil Brasileiro, tanto para as pessoas naturais quanto para as pessoas jurídicas. Em regra, são conceitos próximos, que não se excluem, e servem para a aferição do critério espacial do IPVA.

Logo, conjugando a determinação da Constituição da República de que os Municípios fazem jus à metade da receita do IPVA sobre os veículos licenciados em seus territórios, juntamente às disposições do Código de Trânsito Brasileiro, do Código Tributário Nacional e do Código Civil, chega-se à conclusão de que o critério espacial do IPVA deve ser, necessariamente, o local do registro e licenciamento do veículo, sendo que este só poderá ser feito onde o contribuinte estiver domiciliado.

Evidentemente, se o contribuinte possuir domicílios diversos, localizados em diferentes unidades da Federação, poderá efetuar o registro e o licenciamento do veículo de sua propriedade em qualquer um deles. 
A regra é prática e lógica, pois o contribuinte possivelmente fará maior uso do seu veículo no local onde possua seu domićlio, sendo que a receita obtida com o imposto reverterá para o Estado, o Distrito Federal e respectivo M unicípio do local onde foi o veículo registrado e licenciado, cobrindo os custos da manutenção das vias públicas e outros mais decorrentes do uso do veículo nos limites do Estado. Contudo, é uma solução parcial, já que nem todo veículo automotor depende de licença para ser utilizado e, nestes casos, a solução adotada por alguns Estados foi a instituição de um registro próprio, mantido pela Secretaria da Fazenda, distinto do banco de dados do DETRAN (MAM EDE, 2002, p. 65). Ademais, o critério espacial do registro/domicílio foge da solução ideal de custo-benefício para os Estados, Distrito Federal e Municípios, já que muitos contribuintes, mesmo corretamente pagando o IPVA no Departamento Estadual de Trânsito do Estado (DETRAN) no seu M unicípio, pode fazer uso do veículo em local completamente diverso.

Por fim, há de se mencionar o caso das embarcações e aeronaves. Ainda que grande parte das leis estaduais ordene seu enquadramento como veículo automotor - algo contestado por grande parte da doutrina e da jurisprudência, inclusive do Supremo Tribunal Federal, -, discute-se qual seria o critério espacial para a cobrança do IPVA neste casos, uma vez que o registro de tais veículos é realizado junto a órgãos federais, e não na esfera estadual. A resposta para tal questão pode ser encontrada com o auxílio do Código Tributário Nacional, que prevê como regra geral do critério espacial o domicílio do contribuinte. Destarte, dependerá do fisco estadual ou distrital o emprego das diligências junto aos órgãos públicos federais de registro de embarcações e aeronaves para fins de incidência do IPVA.

\section{A guerra fiscal entre os Estados}

A partilha, entre a União, os Estados, o Distrito Federal e os Municípios, das competências para criar impostos foi levada a cabo de acordo com um critério material. 0 constituinte, desta feita, descreveu objetivamente fatos que podem ser colocados, pelos legisladores originários federal, estaduais, distrital e municipais nas hipóteses de incidência dos impostos de suas pessoas políticas (CARRAZZA, 2007, p. 623). Todavia, somente a utilização do critério material não é suficiente, por si só, para evitar conflitos de competência impositiva entre os entes políticos da Federação. 
Logo, além do critério material, o constituinte levou em conta, para a solução dos possíveis conflitos neste campo, o critério espacial, evitando usurpações de um ente sobre 0 outro.

Reforçando a idéia, os Estados, os M unicípios e o Distrito Federal só podem exigir impostos nos limites de seus territórios. Com efeito, como é sabido e assente, só a lei pode criar tributos (arts. 50, II, e 150, I, da CF). Ora, qualquer lei - aí compreendida, pois, a lei tributária - vigora e é aplicável num espaço físico determinado. Dito de outro modo, ela só pode colher fatos (imputando-lhes os efeitos jurídicos previstos) ocorridos dentro de seu âmbito de validade: 0 território da pessoa política que a editou (CARRAZA, 2007, p. 627).

Sempre que um ente político ultrapassa sua competência tributária constitucionalmente demarcada, amealhando receitas que por direito são devidas a outros entes, surge um desequilíbrio no pacto federativo.

Por vezes os entes se utilizam da vagueza ou da dúvida que permeia determinado critério da hipótese de incidência tributária para amealhar vantagens pecuniárias em detrimento de outros. Noutros casos, a ação do ente político é legítima, mas esta sua ação, mesmo que situada no campo do direito, visa indiretamente atrair a receita de impostos que, doutro modo, nunca Ihe pertenceriam. É o caso típico dos estímulos fiscais que Estados e Municípios oferecem às grandes empresas para que se fixem em seus territórios: conquanto nestes casos tais entes não interfiram na competência alheia, o oferecimento de grandes estímulos cria um desequilíbrio de forças e configura, quase sempre, renúncia de receita por parte do ente concedente.

Em todas essas situações apresentadas, em que existe um conflito de dois ou mais entes políticos dotados de competência tributária sobre a receita provinda de um único fato jurídico tributável, ocorre a chamada guerra fiscal.

No que toca ao imposto sobre a propriedade de veículos automotores (IPVA), a guerra fiscal nasce da imposição de diferentes alíquotas pelos diversos Estados da Federação, alguns onerando mais e outros menos a propriedade do veículo automotor situado no seu território.

Em regra, os Estados que mais oneram seus contribuintes, aplicando altas alíquotas, assistem a uma debandada de contribuintes para os Estados que empregam alíquotas menores, que se beneficiam desta política. 0 conflito entre Paraná e São Paulo constitui um 
caso emblemático, pois as alíquotas praticadas no Paraná são, em regra, menores do que aquelas praticadas em São Paulo e, tratando-se de Estados vizinhos, muitos proprietários paulistas de veículos automotores buscam refúgio no Paraná, licenciando no Estado do Sul seus veículos. O Paraná, como outros Estados que licenciam veículos de contribuintes alienígenas, não busca criar grandes empecilhos ao registro, interessado que está na receita advinda do IPVA destes contribuintes.

Cumpre ressaltar que, possuindo o contribuinte duplo domicílio, em Estados distintos, nenhum obstáculo existe para que ele licencie seu veículo em qualquer um deles. Todavia, o que se testemunha atualmente são casos flagrantes de fraude ao fisco estadual, em que os contribuintes declaram falso domićlio em outro Estado que não o seu de origem para se beneficiar das baixas alíquotas. Como já enfatizado anteriormente, tal atitude configura infração administrativa passível de multa e que pode ensejar, inclusive, a cobrança pelo Estado prejudicado pela fraude.

Parte da doutrina, porém, não se coaduna com a rigidez da regra esposada, tal como o renomado jurista Ives Gandra da Silva Martins (2007, p. 1), que proclama ser um abuso do Estado exigir o pagamento do IPVA do contribuinte que tem domicílio em seu território, pois, segundo o autor, sendo o veículo, por excelência, um bem para locomoção pode ser utilizado em todo o território nacional, e o artigo 150, V, da Constituição Federal proíbe qualquer limitação tributária que represente restrição à livre circulação.

Seja qual for a teoria adotada, é inevitável reconhecer que a atual conjuntura legal favorece a guerra fiscal e enquanto não fixadas as alíquotas mínimas pelo Senado Federal, nos termos do artigo 155, § 6으, da Constituição da República, e não editada Lei Complementar que regule o IPVA em nível nacional, os embates entre os Estados continuarão a existir.

\section{Conclusão}

A hipótese tributária, antecedente ou suposto normativo do imposto sobre a propriedade de veículos automotores (IPVA) é a descrição normativa do evento que, concretizado no mundo fático, dá lugar à relação jurídica tributária entre o Estado ou 0 Distrito Federal (sujeitos ativos) e o contribuinte (sujeito passivo), cujo objeto é a obrigação tributária. A hipótese tributária é composta de três elementos lógicos principais: o critério 
material (núcleo da descrição fática), o critério temporal (condicionante de tempo) e o critério espacial (condicionante de lugar).

Dentre as inúmeras controvérsias que circundam os critérios da hipótese tributária do IPVA, exsurge, como uma das mais significantes, aquela concernente ao critério espacial, ou seja, o plano territorial de aplicação do IPVA.

A Constituição da República não traz regra explícita acerca do critério espacial do IPVA, problema agravado pela inexistência de Lei Complementar que regule esta importante exação. Todavia, há no ordenamento jurídico nacional indícios suficientes que, conjugados através de um método interpretativo histórico-sistemático, apontam para uma única e clara direção: a de que o IPVA é devido no local onde o veículo automotor estiver licenciado, sendo o licenciamento uma imposição legal de observância obrigatória a ser realizado no órgão executivo de trânsito do Estado ou do Distrito Federal localizado no Município do domicílio do proprietário.

A falta de clareza na aplicação do critério espacial, aliada às diferentes alíquotas aplicadas ao IPVA em cada Estado da Federação faz nascer a chamada guerra fiscal, que nada mais é do que o conflito surgido entre dois ou mais entes políticos dotados de competência tributária sobre a receita provinda de um único fato jurídico tributável, no caso em tela, a propriedade de veículo automotor.

A solução para dar fim à guerra fiscal, bem como às fraudes ao fisco estadual, seria a instituição de uma Lei Complementar que regulasse o IPVA em todo o território nacional, estabelecendo parâmetros comuns, bem como a instituição de alíquotas mínimas pelo Senado Federal, nos termos do artigo 155, § 6으, da Constituição da República.

\section{Referências}

CARRAZZA, Roque Antonio. Curso de direito constitucional tributário. 23ạ ed. São Paulo: Malheiros, 2007.

CARVALHO, Paulo de Barros. Curso de direito tributário. 16a ed. São Paulo: Saraiva, 2004.

M AM EDE, Gladston. IPVA: Imposto sobre a Propriedade de Veículos Automotores. São Paulo: Revista dos Tribunais, 2002. 
M ARTINS, Ives Gandra da Silva. IPVA e o direito dos contribuintes. Jus Navigandi. Teresina, ano 12, número 1635, 23 dez. 2007. Disponível em: «ttp://jus2.uol.com.br/doutrina/texto.asp?id=10788>. Acesso em 04 nov. 2008.

SEGUNDO, Hugo de Brito Machado. Direito tributário e financeiro. 2ª ed. 2ª reimpressão. São Paulo: Atlas, 2007. 